\title{
Uso nutricional e terapêutico do leite de cabra
}

\author{
Nutritional and therapeutic use of goat milk
}

\author{
Edson Luis de Azambuja Ribeiro; Horaci Jaqueline Silva de Souza Ribeiro²
}

\begin{abstract}
Resumo: Esta revisão de literatura teve como objetivo descrever a composição e a utilização do leite de cabra na alimentação humana. Por seu alto valor nutricional, boa digestibilidade, boa aceitação e um baixo potencial alergênico, o leite de cabra tem sido recomendado para crianças, pessoas idosas e convalescentes. Porém, o leite de cabra não pode ser recomendado indistintamente para todas as crianças alérgicas ao leite de vaca, pois a sua utilização pode causar, em alguns casos, sérios danos à saúde das mesmas.
\end{abstract}

Palavras-chave: alergia, composição do leite, lactente, valor nutricional.

Abstract: This literature review had as objectives to describe the goats milk composition and its utilization in human feed. Due its good nutritional value, good digestibility and acceptability, and a low allergenic potential, the goat's milk has been recommended for children, elderly and convalescent persons. However, it cannot be recommended to every child allergic to cow's milk, because in some cases, serious threat to life can also occur with goat's milk.

Key words: allergy, milk composition, infant, nutritional value.

\section{Introdução}

A caprinocultura representa uma atividade pecuária importante para a maioria dos países, porém está mais concentrada nas regiões tropicais e ou semi-áridas. A finalidade da atividade tem sido o fornecimento de alimentos e matéria prima de vestuário à população humana. O nível de eficiência da produção de caprinos varia de país para país, em decorrência, principalmente, do nível de desenvolvimento do país (FIGUEIREDO, 1990). Os principais produtos oriundos da atividade são a carne, o leite, a pele, a fibra e o estrume; a importância de cada um destes produtos pode variar de acordo com - local onde a atividade está sendo desenvolvida, a raça criada, entre outros fatores.

A exploração dos caprinos para a produção de leite é bastante antiga, já aparecendo na mitologia grega, onde Zeus teria sido alimentado com leite da cabra Amaltéia (GRIMAL, 1983). A exploração dos caprinos para leite tem crescido, porque além do leite ser considerado um produto de alto valor nutritivo, os caprinos têm a capacidade de se adaptar a condições criatórias variáveis, podendo proporcionar a famílias de baixa renda familiar, e a população em geral, uma melhoria do nível nutricional da dieta (FIGUEIREDO, 1990; MEDEIROS et al., 1994; KNIGHTS; GARCIA, 1997). Segundo Ribeiro (1997) o uso de leite de cabras por indicação médica tem sido um dos carros chefes a promover a caprinocultura leiteira. De acordo com Pellerin (2001), o leite de cabra apresenta propriedades bioquímicas que favorecem seu valor nutricional, sendo recomendado para crianças, particularmente para aquelas intolerantes ao leite de vaca, para pessoas com doenças gastrointestinais, ou mesmo como suplemento para pessoas idosas e malnutridas. As populações dos países em desenvolvimento, onde a caprinocultura é mais importante numericamente, podem ser sensivelmente beneficiadas com a produção de leite caprino (KNIGHTS; GARCIA, 1997; PELLERIN, 2001).

O leite materno, por suas vantagens nutricionais $e$ metabólicas, por seus efeitos psicológicos sobre a mãe e filho na amamentação natural, e pelo papel que desempenha na prevenção de doenças, é o melhor alimento para crianças até os quatro a seis meses de idade (EUCLYDES, 1997; MALDONADO et al., 1998). Segundo Host et al. (1999) este deve ser o alimento único do bebê até esta idade, e seu uso resulta em uma diminuição acentuada das manifestações alérgicas por parte das crianças. Alimentos suplementares devem ser introduzidos apenas após os cinco meses de idade. $\mathrm{O}$ leite de cabra, e de outras espécies, bem como fórmulas especiais, tem sido recomendado para estas crianças, com mais de cinco meses, ou em casos, de crianças mais jovens, onde não houve a possibilidade da amamentação materna. Porém, de uma maneira geral, há falta de conhecimento e muitas crendices em relação ao leite de cabra. Em função disto, esta revisão de literatura teve por objetivo avaliar o uso de leite de cabra na alimentação, principalmente de crianças, e suas conseqüências nutricionais e terapêuticas.

\footnotetext{
${ }_{1}^{1}$ Professor do Departamento de Zootecnia, Centro de Ciências Agrárias, Universidade Estadual de Londrina, Caixa Postal 6001, 86051 970, Londrina, PR. e-mail: <elar@uel.br>.

${ }^{2}$ Nutricionista, aluna do Programa de Pós-graduação em Ciências de Alimentos, TAM/UEL.
} 


\section{Características do Leite}

O leite de cabra é um composto físico e químico complexo. Segundo Le Jaouen (1981), o leite é basicamente uma emulsão de gordura numa solução aquosa, contendo vários elementos, alguns, como a lactose e minerais, estão dissolvidos, e outros em forma coloidal, como os compostos nitrogenados. O leite de cabra possui qualidades próprias, que muito o recomendam como alimento, porém a sua composição varia de acordo com vários fatores, entre estes, a raça, estágio de lactação, ciclo estral, condições ambientais, estação do ano, alimentação, cuidados dispensados ao animal e estado de saúde do mesmo (JARDIM, 1984).

De acordo com Le Jaouen (1981), o leite de cabra apresenta algumas características físicas que o distinguem do leite de vaca. Apresenta um gosto típico, que dependendo de onde os animais estão instalados e da alimentação que recebem, por exemplo, em estábulos mal cheirosos e alimentos odoríferos, podem apresentar um gosto mais forte, muitas vezes indesejável. Porém, se o leite for higienicamente obtido, é muito bem aceito pelas crianças, como observado em um trabalho realizado em creches na cidade de São Paulo, onde se verificou que o leite de cabra teve uma aceitação $50 \%$ maior do que o leite de vaca (SAÚDE, 2001). Apresenta uma acidez natural um pouco menor do que o leite de vaca, com $14^{\circ}$ Dornic ou pH 6,4 . Valores para densidade variam entre 1,026 a 1,042; e o ponto de congelamento é de aproximadamente $-0,58^{\circ} \mathrm{C}$. Por não apresentar caroteno (pró-vitamina $A$ ), e sim vitamina $A$, o leite de cabra apresenta uma coloração branca pura. No leite de vaca, a presença desta pró-vitamina é responsável por sua coloração mais amarelada.

Dados médios para a composição do leite de cabra, vaca e humano, adaptados de compilações de vários autores, são apresentados na Tabela 1. Não sendo observada uma diferença muito marcante entre os leites de cabra e vaca, porém o leite humano apresenta visivelmente menores teores de proteína e minerais, e valores mais elevados para lactose. Porém, pode se observar na literatura diferenças marcantes entre o leite de diferentes raças caprinas (CLARK; SHERBON, 2000), e entre os leites caprino e bovino (HADJIPANAYIOTOU, 1995).

Tabela 1 - Composição média dos leites de cabra, vaca e humano. ${ }^{1}$

${ }^{1}$ Fonte: Adaptado de Jardim (1986), FAO (1987), Medeiros et al. (1994), Euclydes (1997) e Ribeiro (1997).

A lactose dos leites de cabra e vaca é essencialmente a mesma, sendo formada por uma molécula de $\alpha$ ou $\beta$-glicose e uma molécula de $\beta$-galactose. O leite normalmente apresenta pouca variabilidade no teor de lactose, isto ocorre em função da mesma ser um dos principais responsáveis pela osmolaridade, e da necessidade da pressão osmótica do leite estar de acordo com a pressão sanguinea (SWAISGOOD, 1996).
A gordura do leite é composta essencialmente por glicerídeos e esteróides. A gordura forma glóbulos que ficam suspensos no leite como uma emulsão. Estes glóbulos apresentam diâmetros que variam de 1 a 10 microns. O leite de cabra apresenta uma maior percentagem de glóbulos pequenos, sendo que $28 \%$ dos glóbulos são menores do que 1,5 microns, enquanto no leite de vaca este valor é de 10\% (LE JAOUEN, 1981). Este fato explica parcialmente a melhor digestibilidade por parte do leite de cabra quando comparado com o leite de vaca.

Outro ponto importante em relação à gordura do leite, é a sua composição em ácidos graxos (Tabela 2). Diversas análises demonstram que o leite de cabra apresenta $18 \%$ de ácidos graxos de cadeia curta (de 4 a 10 carbonos), ou seja, o dobro do leite de vaca, representado sobre tudo pelos ácidos graxos voláteis capróico, caprílico e cáprico (FURTADO, 1986). Estes ácidos graxos voláteis parecem ser responsáveis pelo sabor característico do leite de cabra.

Tabela 2 - Percentagem de ácidos graxos específicos na gordura dos leites de cabra, vaca e humano, em relação ao total de ácidos graxos. ${ }^{1}$

Segundo a FAO (1987), o tamanho médio dos glóbulos de gordura no leite caprino é de 2,5 a 3,5 microns, sendo que este menor tamanho facilita uma maior dispersão e uma distribuição mais homogênea da gordura. A homogeneização natural do leite de cabra é, do ponto de vista de saúde pública, mais valiosa que a homogeneização mecânica ao qual o leite de vaca é submetido. Quando os glóbulos de gordura são fracionados por ação mecânica, há a liberação da enzima xantina oxidase; esta tem a particularidade de penetrar na parede do intestino e na corrente sangüínea, ocasionando danos ao coração e artérias. Como resposta a isto, o organismo libera colesterol no sangue, o que pode conduzir a um fenômeno de arteriosclerose. No leite de vaca natural, ou seja, não homogeneizado, este problema não ocorre, sendo a enzima normalmente excretada do organismo sem ser absorvida.

As principais proteínas presentes no leite podem ser divididas em três grupos (LE JAOUEN, 1981; SWAISGOOD, 1996): 1) Caseína, que é a parte coagulável das proteínas, e é representada em ordem decrescente pela $\alpha_{\mathrm{s}}$-caseína $\left(\alpha_{\mathrm{s} 1}\right.$ e $\left.\alpha_{\mathrm{s} 2}\right)$, $\beta$-caseína, $\kappa$-caseína e $\gamma$-caseína. 2) Proteínas solúveis não coaguláveis, 
representadas pela $\beta$-lactoglobulina, $\alpha$-lactoalbumina. 3) Proteoses, peptonas, albumina sérica e imunoglobulinas, as quais ocorrem em baixas concentrações.

Como observado na Tabela 1, praticamente não há diferença no teor de proteína bruta dos leites de vaca e cabra, porém, a constituição desta proteína é que muda. Segundo Pierre (1977) apud Le Jaouen (1981), a $\alpha_{\mathrm{s}}$ caseína representa $21,2 \%$ da proteína do leite de cabra, enquanto no leite de vaca, este valor corresponde a $40 \%$. Por outro lado, a $\beta$-caseína representa $67,4 \%$ da proteína do leite de cabra e 43,3\% da proteína do leite de vaca. Clark e Sherbon (2000) citam que os leites de cabra e vaca tem proporções similares de א-caseína e $\alpha_{\mathrm{s} 2}$-caseína, porém o leite de cabra apresenta níveis mais altos de $\beta$-caseína (53\% vs 37,5\%) e níveis mais baixos de $\alpha_{s 1}$-caseína (15\% vs 38\%) do que o leite de vaca. O leite de cabra também apresenta menor percentagem de proteínas do soro do que o leite de vaca, respectivamente, 0,43 e 0,60\% (RIBEIRO, 1997).

Da mesma maneira o tamanho das micelas de caseína varia entre as espécies. Barbaro e Calapaj (1958) apud Le Jaouen (1981) encontraram maior freqüência de micelas de caseína com diâmetros de 50 e 75 nm em leites de cabra e vaca, respectivamente. O tamanho das micelas depende do tipo de caseína observada, por exemplo, em micelas maiores são encontrados maiores teores de $\alpha_{s_{2}}$-caseína, por outro lado, em micelas menores há maiores teores de א-caseína (PIERRE et al., 1999). Vegarud et al. (1999) na Noruega, observaram grande variação no tamanho das micelas presentes no leite de cabras de diferentes rebanhos e entre indivíduos do mesmo rebanho.

De acordo com a FAO (1987), a ausência ou menor quantidade de $\alpha_{\mathrm{s} 1}$-caseína encontrada no leite de cabra faz com que o coágulo formado por ação da renina seja menor e com granulação mais fina e macia do que os formados no leite de vaca.

Segundo Walker (1991), a diferença mais marcante entre os leites de cabra, vaca e humano é a grande quantidade de caseína presente no leite de cabra e vaca, quando comparada com a pequena quantidade presente no leite humano. Além de uma maior taxa de albumina e globulina, em relação à caseína no leite humano.

Os minerais representam uma pequena fração do leite, variando muito pouco entre raças e em função de fatores ambientais (Tabela 3 ). Nem todos os minerais estão presentes na forma de sais solúveis, mas uma importante parte está em fase coloidal. Aproximadamente $67 \%$ do cálcio e mais da metade do fósforo são partes do complexo com a caseína, conhecido como micela de caseína (LE JAOUEN, 1981).

A composição vitamínica dos leites de cabra, vaca e humano são apresentados na Tabela 4. Com a exceção dos menores conteúdos de ácido fólico, vitamina $\mathrm{C}$ e inositol, o leite de cabra tem composição similar ao leite humano. O leite de cabra apresenta menos vitaminas B6 e B12 do que o leite de vaca, porém isto não representa problemas nutricionais, pois estes teores não são menores do que se observa no leite humano.
Tabela 3 - Composição mineral dos leites de cabra, vaca e humano. ${ }^{1}$

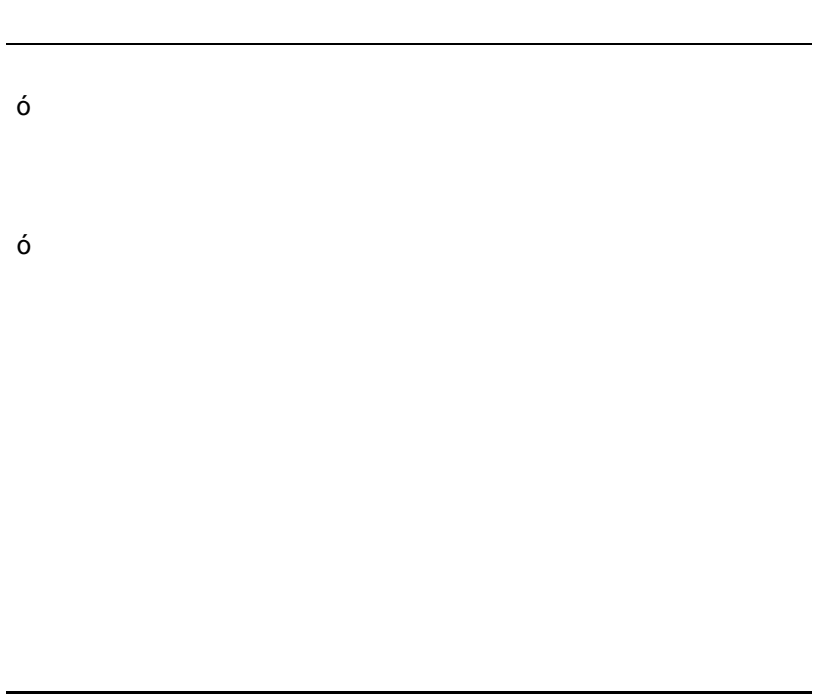

Tabela 4 - Composição vitamínica dos leites de cabra, vaca e humano.

Segundo Jardim (1984), as raças caprinas leiteiras, em média, produzem um leite semelhante ao leite bovino quanto à composição, porém mais pobre em albumina e globulina. Ambos são pobres em ferro e cobre, mas satisfatórios em cálcio e fósforo. São equivalentes nas taxas de vitamina $A$ e $D$, são pobres em vitamina $C$, sendo o leite de cabra paupérrimo em vitamina $E$.

Gall (1981) comenta que não há diferenças marcantes entre o leite de cabra e de vaca no que diz respeito à composição, e há divergências quanto a maior digestibilidade do leite caprino. Porém, segundo Jardim (1984) e Pinheiro Júnior (1985), o leite de cabra é um alimento dotado de alto valor nutritivo e de fácil digestão. A alta digestibilidade decorre do reduzido tamanho e da grande dispersão dos glóbulos graxos, assim como das características próprias de sua caseína, que, durante a digestão, forma coágulos menos resistentes e mais friáveis que os do leite de vaca e que podem ser desintegrados mais rapidamente pelas enzimas proteolíticas. 
Apesar de todas as diferenças observadas, ou sugeridas, entre os leites de vaca e cabra, em um trabalho visando recuperar crianças de 1 a 5 anos subnutridas e hospitalizadas, através da administração de leite de vaca ou de cabra, observou-se ganhos de peso médios similares $(P>0,05)$ entre os grupos, respectivamente, 7,8 e $8,5 \mathrm{~g} / \mathrm{kg} / \mathrm{dia}$ (RAZAFINDRAKOTO et al., 1994). Sendo concluído que os dois tipos de leite são nutricionalmente similares.

\section{Algumas Recomendações Específicas para o Uso do Leite de Cabras}

De acordo com Jardim (1984) e Medeiros et al. (1994) o leite de cabra é o alimento ideal para crianças, pessoas idosas, doentes e convalescentes, pois além de ter boa composição nutricional, não provoca o aparecimento de cólicas estomacais, podendo mesmo, em alguns casos, eliminá-las. Também é recomendado para crianças alérgicas ao leite de vaca e a pessoas que fazem tratamento quimioterápico, porque pode diminuir a queda de cabelos, que ocorre com este tipo de tratamento.

Segundo Haenlein (1992) apud Knights e Garcia (1996) o leite de cabra é rico em ácidos graxos com cadeias curtas, tais como o cáprico e caprílico. Sendo esses ácidos graxos comumente usados em tratamentos de pessoas com problemas de má absorção, pois têm habilidade única de prover energia, além de inibir e limitar a deposição de colesterol nos tecidos e dissolver as placas de colesterol.

Em 300 casos de asma em que a alergia a lactoalbumina do leite de vaca foi diagnosticada como a principal causa, 270 tornaram-se livres dos sintomas em seis semanas, após substituírem o leite de vaca pela mesma quantidade de leite de cabra (WALKER, 1991). De maneira semelhante, dados de muitas pesquisas mostram que aproximadamente $10 \%$ da população, tanto adultos como crianças, sofre enxaqueca, e que parte desta é devido à alergia à alimentação. Walker (1991) observou que em 1.682 pacientes com enxaqueca alérgica, aproximadamente $80 \%$ tinham o problema devido ao consumo de leite de vaca e queijo de leite de vaca, por serem alérgicas a lactoalbumina deste leite.

O leite de cabra apresenta uma capacidade tampão (buffer) superior ao leite de vaca, sendo mais recomendado então, para pessoas em tratamento de úlceras gástricas. Os principais componentes tamponantes do leite são as proteínas e os fosfatos (FAO, 1987).

Ainda, segundo Pinheiro Júnior (1985), a excelência do leite de cabra, como substituto do leite materno, revelou-se nas experiências realizadas, na grande luta mantida em todo o mundo contra a tuberculose. Foi verificado por inúmeros médicos que a porcentagem de crianças tuberculosas diminuía com o uso do leite de cabra, em substituição ao de vaca. Isto é, provavelmente, devido a menor incidência da doença nos caprinos, o que tornaria o leite mais seguro.
De acordo com Pinheiro Júnior (1985), alguns autores atribuem qualidades afrodisíacas, ou melhor, estimulantes, ao leite de cabra, tornando-o muito salutar aos mais velhos. Esta ação seria devido ao ácido cáprico. O autor cita como prova disto, a extraordinária vitalidade do célebre líder hindu, Mahatma Ghandi, que sempre tomava leite de cabra, fazendo-se acompanhar, em suas viagens, por uma excelente cabra leiteira. Porém, não há nenhuma conclusão científica a este respeito. Sendo provavelmente mais um folclore a respeito deste animal.

\section{Problemas com o Uso do Leite de Cabras}

O leite de cabra é acusado de provocar anemia em crianças com ele alimentadas. Tal afirmação precisa ser examinada, pois o leite de vaca às vezes sofre a mesma restrição. Acredita-se que a anemia não deve ser atribuída ao leite de cabra em si, mas sim a ingestões insuficientes das vitaminas B6 e B12, assim como a carências de ferro, cobalto e ácido fólico (JARDIM, 1984). O leite de cabra apresenta baixos níveis de ácido fólico, vitaminas B12 e C (EUCLYDES, 1997). Segundo Pinheiro Júnior (1985), uma das razões para a anemia causada pelo leite de cabra, seria a baixa taxa de ferro disponível contida neste leite, pois que somente $22 \%$ do ferro é assimilável, quando no leite humano esta taxa é de $80 \%$.

De acordo com Walker (1991), a anemia nutricional pode ocorrer, independentemente do tipo de leite. Esta anemia pode ser curada ou prevenida adequadamente, adicionado-se ferro e cobre ao leite, de qualquer espécie animal, juntamente com o aconselhamento médico às mães, no sentido de adotar dieta variada na alimentação dos bebês.

Por apresentar uma elevada carga de solutos, o leite de cabra apresenta um risco de desidratação hipernatrêmica e acidose metabólica a crianças com menos de seis meses alimentadas com este leite (EUCLYDES, 1997). O leite de vaca apresenta o mesmo problema.

\subsection{Alergia}

Os principais alérgenos encontrados no leite de vaca parecem ser a $\beta$-lactoglobulina, que não aparece no leite materno, a caseína, a $\alpha$-lactoalbumina e a albumina sérica. Del Val et al. (1999) citam a $\beta$-lactoglobulina como o principal alérgeno do leite bovino.

Walker (1991) cita que crianças alérgicas ao leite podem pertencer a um dos seguintes grupos: aquelas que são alérgicas a um fator espécie-específico da lactoalbumina bovina; aquelas sensíveis a um fator comum a todas as lactoalbuminas animais (mas não as humanas); e aquelas sensíveis à caseína. Segundo a autora, a maior parte pertence ao primeiro grupo, ou seja, sensíveis a lactoalbumina bovina, os quais apresentam resultados positivos quando tratados com leite de cabra.

Entre os sintomas apresentados na alergia estão o eczema infantil, náusea, dor abdominal e distúrbios epigástricos. Ocasionalmente, o leite de vaca pode 
causar sintomas agudos de choque, diarréia, vômito e convulsão. A medida que a criança alérgica cresce, os sintomas de eczema e os distúrbios digestivos desaparecem. Se sua alergia permanece sem tratamento, na idade de 5-6 anos, os sintomas podem ser asma, colite, enxaqueca e descarga nasal (WALKER, 1991).

Os fenômenos alérgicos parecem ser hoje mais comuns do que a algum tempo atrás, especialmente para crianças jovens. De acordo com Madsen (1997), não existe uma estimativa completamente segura da prevalência de alergia e intolerância a alimentos na Europa. Porém, a autora cita que na população adulta européia, aproximadamente $5 \%$ sofrem com problemas de alergia e intolerância a algum tipo de alimento. Em crianças dinamarquesas com 18 meses de idade, a prevalência é ao redor de 6,5\%; aproximadamente $2 \%$ das crianças com até 1 ano de vida, são alérgicas especificamente ao leite de vaca.

Os principais responsáveis por alergia e intolerância observadas em crianças européias são o leite, ovos, peixes e laranjas. Um problema que tem sido observado, é que muitos indivíduos apresentam intolerância múltipla, tornando-se difícil o tratamento (MADSEN, 1997; CARROCCIO et al., 2000).

No final da década de 50, ao redor de $6 \%$ das crianças nos Estados Unidos apresentavam respostas alérgicas ao consumo de leite de vaca nos primeiros meses de vida, acredita-se que este índice tenha aumentado, devido ao aumento do número de bebês alimentados artificialmente, em função da menor freqüência do hábito de amamentação natural. Apesar do leite de cabra não aliviar todos os processos alérgicos induzidos pelo leite de vaca, tem-se observado bons resultados na maioria dos casos; sendo bastante recomendado por muitos médicos (FAO, 1987; WALKER, 1991).

Em função de problemas que podem ocorrer com o uso do leite de vaca, o Comitê de Nutrição da Academia Americana de Pediatria desaconselha o seu uso durante o primeiro ano de vida (EUCLYDES, 1997). Walker (1991), em sua atuação como médica em clínicas de alergia e em pesquisas por um período de 25 anos, constatou que apenas um caso em cem (1\%), de crianças que eram alérgicas ao leite de vaca, nas quais o uso de leite de cabra não pode corrigir a alergia.

Porém, apesar dos bons resultados apresentados acima, vários trabalhos realizados em laboratório ou com indivíduos alérgicos a proteína do leite de vaca, testaram como alternativa o uso de leite de cabra, e observaram que as reações alérgicas continuaram, onde concluíram que o leite de cabra não deve ser usado como um substituto para crianças alérgicas a proteína do leite de vaca (DEAN et al., 1993; SPUERGIN et al., 1997; BELLIONI-BUSINCO et al., 1999; RESTANI et al., 1999). Spuergin et al. (1997) compararam o potencial alergênico da $\alpha$-caseína dos leites de vaca, cabra e ovelha, e observaram uma alta reatividade cruzada entre estes leites, o que segundo os autores foi devido a grande similaridade entre estas proteínas, que possuem mais de $85 \%$ de aminoa-ácidos idênticos. Resultados como esses, levaram a Sociedade Européia de Alergologia Pediátrica e Imunologia Clínica e a Sociedade de Gastroenterologia Pediátrica, Hepatologia e Nutrição a emitir um parecer conjunto sugerindo que dietas baseadas em proteínas não modificadas de leites de cabra e ovinos, entre outras espécies, ou em fórmulas infantis com proteínas parcialmente hidrolisadas não devem ser usadas no tratamento da alergia a proteína do leite de vaca.

Segundo Bahna (1996) as alergias causadas pelo consumo de proteína do leite de vaca e pelo consumo de lactose são muitas vezes mal diagnosticadas, pois os sintomas podem ser semelhantes. Porém, no caso da proteína do leite de vaca há uma reação de hipersensibilidade, podendo levar a morte, tendo prevalência de 3 a $5 \%$, e ocorre principalmente em crianças jovens. Sendo o tratamento básico a eliminação completa do leite. Normalmente é temporária. Já a intolerância a lactose, é uma desordem gastrointestinal benigna, causada pela deficiência da enzima lactase necessária à digestão da lactose. Ocorre principalmente com adolescentes e adultos. Alguns povos são mais susceptíveis, a prevalência entre asiáticos, índios americanos, esquimós e negros, é de 70 a $90 \%$. Muitos indivíduos toleram pequenas quantidades de leite ou produtos processados, tais como iogurte e queijos maturados. Preparados de lactase comercial podem ser tomados antes de se ingerir o leite ou acrescentados ao próprio leite. Este é um problema para toda a vida, com exceção de quando ocorre como uma conseqüência secundária a uma doença gastrointestinal aguda. Os resultados obtidos por Verwimp et al. (1995) e Pelto et al. (1998), mostram que indivíduos alérgicos a proteína do leite e intolerantes a lactose formam grupos distintos, ou seja, os alérgicos a proteína do leite de vaca, geralmente não são intolerantes à lactose. Apesar da alergia a proteína do leite ser considerada uma doença principalmente de crianças, Pelto et al. (1999) estimaram prevalências entre 3 a $6 \%$ da população adulta na Finlândia.

A lactose é um dissacarídeo composto por glicose e galactose, porém não pode ser absorvida como tal, necessitando ser hidrolisada por ação da lactase intestinal. A lactose desempenha importantes funções biológicas, entre as quais, o favorecimento da absorção do cálcio, estimula o crescimento das bifidobactérias, e suplementação de galactose, que é um nutriente essencial à formação dos galactolipíos cerebrais (MALDONADO et al., 1998). Indivíduos intolerantes a lactose presente no leite de vaca, também serão intolerantes ao leite de cabra. A presença de lactose no intestino sem ser digerida, é a causa do aparecimento de vários sintomas, entre estes a formação de gases, diarréia, náuseas e cólicas abdominais (FAO, 1987).

Em relação a intolerância a lactose, Maldonado et al. (1998) citam que é comum encontrar-se intolerância como uma conseqüência secundária de certas doenças gastrointestinais, ou como conseqüência da inflamação ou destruição das microvilosidades intestinais. Por outro lado, a deficiência congênita de lactase é uma ocorrência rara. Em ambos os casos, o leite e produtos lácteos 
devem ser excluídos da dieta. Porém, segundo Tamm (1994), as táticas de manejo para controlar a intolerância a lactose dependem do tipo da hipolactasia, da severidade da intolerância e da idade do paciente, e basicamente podem ser a redução do conteúdo da lactose no alimento, e ou o consumo de produtos lácteos especiais, ou o consumo de lactase exógena.

Têm sido observados, esporadicamente, casos de indivíduos intolerantes ao leite de cabra e de ovelha, e serem tolerantes ao leite de vaca (UMPIERREZ et al., 1999). Alguns outros leites, como de asno e camelo, têm sido recomendados para crianças e pessoas alérgicas ao leite de vaca e cabra, com resultados relativamente bons (RESTANI et al., 1999; CARROCCIO et al., 2000). O maior problema nestes casos, é a dificuldade da obtenção destes leites, já que não são espécies facilmente encontradas no nosso meio. Em casos onde o leite não modificado de outras espécies, não puder ser utilizado, têm sido recomendada fórmulas infantis com proteínas altamente hidrolisadas ou a base de soja (VERWIMP et al., 1995; MALDONADO et al., 1998). A hidrólise da proteína é obtida pela quebra da mesma pelo calor e por hidrólise enzimática. Porém, mesmo neste caso pode haver alguns problemas, como, o gosto não tão agradável, alto custo, e alto grau de osmolaridade, o qual pode provocar diarréia osmótica e afetar diretamente o enterocisto (MALDONADO et al., 1998).

\section{Conclusões}

A boa digestibilidade e aceitabilidade do leite de cabra são importantes no momento de se formular dietas para crianças e pessoas convalescentes.

Em muitos casos o leite de cabra pode com êxito substituir o leite de vaca na alimentação de indivíduos alérgicos ao leite de vaca, sendo recomendada à orientação médica neste sentido.

Apesar do leite de cabra apresentar características nutricionais que o destacam do leite de outras espécies, sendo um alimento nobre, ainda há a necessidade de pesquisas científicas para melhor utilizá-lo como alimento para crianças alérgicas.

\section{Referências}

BAHNA, S.L. Is it milk allergy or lactose intolerance? Immunology and Allergy Clinics of North America, v.16, n.1, p.187-198, 1996.

BELLIONI-BUSINCO, B. et al. Allerginicity of goat's milk in children with cow's milk allergy. Journal of Allergy and Clinical Immunology, v.103, n.6, p.1191-1194, 1999.

CARROCCIO, A. et al. Intolerance to hydrolyzed cow's milk proteins in infants: Clinical characteristics and dietary treatment. Clinical and Experimental Allergy, v.30, n.11, p.1597-1603, 2000.

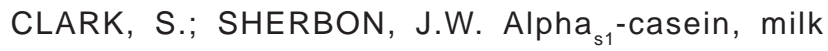
composition and coagulation properties of goat milk. Small Ruminant Research, v.38, p.123-134, 2000.
DEAN, T.P. et al. In vitro allergenicity of cow's milk substitutes. Clinical and Experimental Allergy, v.23, n.3, p.205-210, 1993.

DEL VAL, G. et al. Thioredoxin treatment increases digestibility and lowers allergenicity of milk. Journal of Allergy and Clinical Immunology, v.103, n.4, p.690-697, 1999.

EUCLYDES, M.P. Nutrição do lactente: base científica para uma alimentação adequada. Viçosa: UFV, 1997. 461 p.

FOOD AND AGRICULTURE ORGANIZATION OF THE UNITED NATIONS - FAO. Tecnologia de la producción caprina. Santiago: FAO, 1987. 242 p.

FIGUEIREDO, E.A.P. Perspectivas da produção de caprinos nas próximas décadas na américa latina. In: CAPRINOCULTURA e Ovinocultura. Piracicaba: FEALQ/ SBZ, 1990. p. 69-83.

FURTADO, M.M. Fabricação de queijo de leite de cabra. São Paulo: Nobel, 1986. 126 p.

GALL, C. 1981. Milk production. In: GALL, C. (Ed.). Goat production. London: Academic Press. p. 309-344.

GRIMAL, P. A mitologia grega. 2 ed. São Paulo: Brasiliense, 1983. $123 \mathrm{p}$.

HADJIPANAYIOTOU, M. Composition of ewe, goat and cow milk and of colostrum of ewe and goats. Small Ruminant Research, v.18, p.255-262, 1995.

HOST, A. et al. Dietary products used in infants for treatment and prevention of food allergy. Joint statement of the european society for paediatric allergology and clinical immunology (ESPACI) committee on hypoallergenic formulas and the european society for paediatric gastroenterology, hepatology e nutrition (ESPGHAN) committee on nutrition. Archives of Disease in Childhood, v.81, n1, p.80-84, 1999.

JARDIM, W.R. Criação de caprinos. São Paulo: Nobel, 1984. $239 \mathrm{p}$.

KNIGHTS, M.; GARCIA, G.W. The status and characteristics of the goat (Capra hircus) and its potential role as a significant milk producer in the tropics: A review. Small Ruminant Research, v.26, p.203-215, 1997.

LE JAOUEN, J.C. Milking and the technology of milk and milk products. In: GALL, C. (Ed.). Goat production. London: Academic Press, 1981. p. 345-377.

MADSEN, C. Prevalence of food allergy / Intolerance in Europe. Environmental Toxicology and Pharmacology, v.4, n.1-2, p.163-167, 1997.

MALDONADO, J. et al. Special formulas in infant nutrition: A review. Early Human Development, v.53, supplement 1, p.23-32, 1998.

MEDEIROS, L.P. et al. Caprinos: Princípios básicos para sua exploração. Brasília: EMBRAPA-SPI, 1994. 177 p.

PELLERIN, P. Goat's milk in nutrition. Annales Pharmaceutiques Francaises, v.59, n.1, p.51-62, 2001.

PELTO, L. et al. Milk hypersensitivity - Key to poorly defined gastrintestinal symptoms in adults. Allergy: European Journal of Allergy and Clinical Immunology, v.53, n.3, p.307310, 1998.

PELTO, L. et al. Milk hypersensitivity in young adults. European Journal of Clinical Nutrition, v.53, n.8, p.620-624, 1999. 
PIERRE, A.; MICHEL, F.; ZAHOUTE, L. Composition of casein micelles in relation to size in goat milks with $A$ and null $\alpha_{\text {s1 }}$-casein variants. International Dairy Journal, v.9, p.179-182, 1999.

PINHEIRO JÚNIOR, G.C. Caprinos no Brasil. Belo Horizonte: Itatiaia, 1985. 177 p.

RAZAFINDRAKOTO, O. et al. Goat's milk as a substitute for cow's milk in undernourished children: A randomized double-blind clinical trial. Pediatrics, v.94, n.1, p.65-69, 1994.

RESTANI, P. et al. Cross-reactivity between milk proteins from different animal species. Clinical and Experimental Allergy, v.29, n.7, p.997-1004, 1999.

RIBEIRO, S.D.A. Caprinocultura: criação racional de caprinos. São Paulo: Nobel, 1997. 318 p.

SAÚDE. Leite de cabra, campeão entre a criançada. Saúde, n.209, p.12, 2001.

SPUERGIN, P. et al. Allergenicity of a-caseins from cow, sheep, and goat. Allergy: European Journal of Allergy and Clinical Immunology, v.52, n.3, p.293-298, 1997.
SWAISGOOD, H.E. Characteristics of milk. In: FENNEMA, O.R. (Ed.). Food chemistry. New York: Marcel Dekker, 1996. p. 841-878.

TAMM, A. Management of lactose intolerance. Scandinavian Journal of Gastroenterology, v.29, n.202, p.55-63, 1994.

UMPIERREZ, A. et al. Allergy to goat and sheep cheese with good tolerance to cow cheese. Clinical and Experimental Allergy, v.29, n.8, p.1064-1068, 1999.

VEGARUD, G.E. et al. Genetic variants of Norwegian goats milk composition, micellar size and renneting properties. International Dairy Journal, v.9, p.367-368, 1999.

VERWIMP, J.J.M. et al. Symptomatology and growth in infants with cow's milk protein intolerance using two different wheyprotein hydrolysate based formulas in a primary health care setting. European Journal of Clinical Nutrition, v.49, supplement 1, p.39-48, 1995.

WALKER, V. Uso terapêutico do leite de cabra na medicina moderna. Agropecuária Alternativa, v. 5, n. 25, p. 10-11, 1991. 
